\title{
The effects of genetic polymorphisms of APOE on circulating lipid levels in middle- aged and elderly chinese Fujian Han population: toward age- and sex- personalized management
}

Xiaofeng Liu ${ }^{1,2,3^{*}}$, Qingwen Lin ${ }^{1}$, Kengna Fan ${ }^{1}$, Minjie Tang ${ }^{1}$, Weiqing Zhang ${ }^{1}$, Bin Yang ${ }^{1,2,3}$ and Qishui Ou ${ }^{1,2,3^{*}}$

\begin{abstract}
Background: Increased evidence has reported the association of genetic polymorphisms of Apolipoprotein $E$ (APOE) with serum lipids. However, few studies have explored the combined effects of APOE, gender, and age.

Methods: A total of 1,419 middle-aged and elderly subjects were randomly selected and studied. The APOE genotypes and the serum lipids were detected. The effects of APOE, gender, and age on serum lipids were preliminarily observed in general. The subjects were then divided into the middle-aged group (40-64 years old) and the elderly group ( $\geq 65$ years old), for both males and females, to explore the combined effects of the APOE, gender, and age on serum lipids. Finally, a multivariate logistic regression model was used to evaluate the associations between the APOE allele carriers and the at-risk levels of dyslipidemia.

Results: The serum TC, LDL-C, and ApoB in the $\varepsilon 2$ carriers were lower than the $\varepsilon 3$ carriers (all $P<0.05$ ), and there was no significant difference in the $\varepsilon 4$ carriers compared to the $\varepsilon 3$ carriers in general (all $P>0.05$ ). The serum LDL$C$ and $A p o B$ of the $\varepsilon 2$ carriers were lower than the noncarriers in the middle-aged and elderly males (all $P<0.05)$. The serum TC in the $\varepsilon 2$ carriers was lower than the noncarriers only in middle-aged males $(P<0.05)$. As to the levels of serum HDL-C and ApoA1, the $\varepsilon 2$ carriers were higher than the noncarriers in middle-aged females (all $P<$ $0.05)$, and the $\varepsilon 4$ carriers were lower than noncarriers in middle-aged males $(P<0.05)$. Especially, the serum TG in the $\varepsilon 4$ carriers was significantly higher than the noncarriers in elderly females. The logistic regression analysis indicated that the $\varepsilon 2$ carriers were less likely to have at-risk levels of high LDL-C in middle-aged and elderly males (all $P<0.05$ ) versus low HDL-C in middle-aged females $(P<0.05)$. In contrast, the $\varepsilon 4$ carriers were more likely to have at-risk levels of high TG in elderly females $(P<0.05)$.

Conclusions: The effects of the genetic polymorphisms of APOE on the serum lipids were both gender- and agedependent in the middle-aged and elderly Chinese Fujian Han population.
\end{abstract}

Keywords: Apolipoprotein E, Genetic polymorphism, Serum lipids, Gender, Geriatrics

\footnotetext{
*Correspondence: liuchognyang555@126.com; ouqishui@fjmu.edu.cn 'Department of Laboratory Medicine, the First Affiliated Hospital of Fujian Medical University, 20 Chazhong Road, 350005 Fuzhou, China

Full list of author information is available at the end of the article
} 


\section{Introduction}

With the acceleration of China's aging population, the health of the elderly has attracted more and more attention [1]. The aging population will endure more chronic medical conditions such as cardiovascular disease, diabetes mellitus, and stroke, which have become the major morbidity and mortality [2]. Dyslipidemia is a well-established risk factor of these chronic diseases [3, 4]; however, our understanding of age-related dyslipidemia is still incomplete.

Serum lipids are strongly influenced by smoking, diet, levels of physical activity, and other lifestyles choices. However, the studies from twins and families suggest that the genetic factors are involved in the variation of serum lipids [5, 6]. Apolipoprotein E (APOE), as a critical apolipoprotein, plays a central role in cholesterol metabolism and transport. The APOE gene, as a commonly investigated polymorphic genetic marker, encoded three major alleles: $\varepsilon 2$, $\varepsilon 3$, and $\varepsilon 4$, composed of six genotypes: $\varepsilon 3 / \varepsilon 3, \varepsilon 3 / \varepsilon 4, \varepsilon 2 / \varepsilon 3, \varepsilon 2 / \varepsilon 4, \varepsilon 2 / \varepsilon 2$, and $\varepsilon 4 /$ $\varepsilon 4$. The $\varepsilon 3 / \varepsilon 3$ genotype was considered a "wild type" because it is the widest distribution of the populations [7]. Human ApoE is a $34-\mathrm{kDa}$ protein comprised of three common isoforms (ApoE2, ApoE3, and ApoE4) [8]. Previous studies have shown that serum lipids are under genetic influence by the APOE polymorphisms [9-11]. However, most studies were conducted in the general population. Few studies were performed on the middle-aged and elderly population, particularly in the Chinese Han population of Fujian Province located on the southeast coast of China.

Additionally, it has been reported that gender is involved in lipid and lipoprotein metabolism [12, 13]. The changes in serum lipid levels exist in gender differences during aging [14]. Increased evidence has identified the association between sex-specific genetic and serum lipids $[15,16]$. The combined effects of APOE genetic polymorphism, sex and age on the serum lipids during aging were less reported, which would provide some valuable insight on the individualized lipid management for the aging population. This study aimed to explore the effects of APOE genetic polymorphisms on serum lipids in the middle-aged and elderly Chinese Han population of $\mathrm{Fu}$ jian Province and observed whether these effects exhibit gender-and age-specificity during aging.

\section{Methods}

\section{Study population}

In the present study, 1503 subjects located in Fujian Province were enrolled initially. 46 subjects were excluded because the clinical data were incomplete, and 38 subjects were excluded due to insufficient biological specimen sampling. Finally, we enrolled 1419 middle-aged and elderly subjects (aged 40 years and above) who had received routine health check-ups at the First Affiliated Hospital of Fujian Medical University (Fuzhou, China) between June 2017 and June 2021. All participants were Chinese with Han ethnicity, born in Fujian, and lived in Fujian Province (China). Those who were not born in Fujian and just lived in Fujian Province were currently excluded. The others suffering from severe cardiac diseases, kidney and pulmonary diseases, infective diseases, tumors, diabetes mellitus, chronic liver disease, and subjects with shorter survival time were excluded. The study was performed following the Declaration of Helsinki and was approved by the ethics committees of the First Affiliated Hospital of Fujian Medical University (No, MRCTA, ECFAH of FMU,2018[046]). The written informed consent was obtained from the participants or their surrogates before the study.

\section{Serum lipid parameters measurement}

Peripheral venous blood $(3 \sim 5 \mathrm{~mL})$ was collected from all subjects after at least $12 \mathrm{~h}$ of fasting. Centrifuged at $1,500 \mathrm{~g}$ for $10 \mathrm{~min}$ for getting serum as soon as possible, then stored at $-80{ }^{\circ} \mathrm{C}$ until used. An automatic biochemistry analyzer (Siemens, ADVIA2400) was used to examine the levels of serum lipids, including serum high-density lipoprotein cholesterol (HDL-C), low-density lipoprotein cholesterol (LDL-C), total cholesterol (TC), triglyceride (TG), ApolipoproteinA1 (ApoA1), and Apolipoprotein B (ApoB).

\section{Apolipoprotein E genotype analysis}

The APOE genotypes were determined according to our previous methods [17]. Briefly, the genomic DNA was extracted from peripheral blood leukocytes by a DNA extraction kit (Qiagen, Hamburg, Germany). The extracted DNA quality was evaluated by a NanoDrop 1000 spectrophotometer (Thermo Fisher, Waltham, MA, USA). The genotype of APOE was detected using a commercial DNA Chip Detection kit (Zhuhai Sinochips Bioscience Co., Ltd, Guangdong, China), which has been approved by the CFDA (China Food and Drug Administration), according to the manufacturer's instructions. Then, the human APOE fragments, including two SNP's (rs429358 (Cys112Arg) and rs7412 (Arg158Cys), were amplified by PCR, and the PCR products were hybridized through the specific probe. The hybrid product was colored by the chromogenic agent, and the images in the chip were scanned and the genotype was determined. At the same time, the APOE genotype was further confirmed by Sanger sequencing and blasted in the GenBank [18]. The primers for the Sanger sequencing are as follows: forward primer (5'->3'), GACCATGAAGGAGT TGAAGGCCTAC; reverse primer (5'>> '), CTCGCGGG CCCCGGCCTGGTA. 


\section{Statistical analysis}

Data analysis was performed using the SPSS 20.0 software (Chicago, USA). For continuous variables, the data were expressed as the mean \pm standard deviation (SD), and the categorical variables were represented as a number (\%). The Hardy-Weinberg equilibrium in all participants was examined. Using the independent $t$-test, one-way ANOVA, or the Chi-square test to compare the outcomes. To evaluate the combined effects of APOE genotype, gender and age on serum lipids, we used the logistic regression models to analyze the associations between APOE alleles carrier and at-risk levels of serum dyslipidemia. The BMI, smoking, drinking, education, and physical activity were critically adjusted as confounding factors. The statistical significance was set as $P<0.05$, and all tests were two-tailed.

\section{Results}

\section{General characteristics of the participants}

The characteristics of the studied subjects and serum lipids are shown in Table 1 . There were 795 males $(56.03 \%)$ and 624 females $(43.97 \%)$, and the average age was $59.18 \pm 12.53$ years and ranged from 40 to 91 years. The average BMI (body mass index) of all participants was $24.96 \pm 3.34$, for males was $24.92 \pm 3.62$, and for females was $25.45 \pm 4.02$. Meanwhile, $12.94 \%$ of the subjects reported having the habit of smoking, including $31.71 \%$ for males and $0.94 \%$ for females $(P<0.05)$. Additionally, $18.75 \%$ of the subjects reported having the habit of drinking, including $32.06 \%$ for males and $9.84 \%$ for females $(P<0.05)$, and $36.91 \%$ of the subjects reported no exercise, including $37.56 \%$ for males and $36.82 \%$ for females $(P>0.05)$.
As to the profiles of serum lipids, the serum TC, HDL-C, ApoA1, and the ratio of ApoA1 and ApoB (referred to as $\mathrm{A} 1 / \mathrm{B}$ ) in females were higher than males (all $P<0.05$ ), while the serum TG in males was significantly higher than in females $(P<0.05)$. No significant differences were found in the serum LDL-C and ApoB between males and females (all $P>0.05$ ). These data indicated a significant sex difference of serum lipids in the middle-aged and elderly Chinese Han population in Fujian Province.

\section{APOE allele frequencies and genotypes}

First, the Hardy-Weinberg equilibrium in all subjects was estimated, and the APOE allelic frequency was following Hardy-Weinberg equilibrium $(P=0.17>0.05)$. As shown in Table 2, we identified the six common genotypes of APOE, and the genotype $\varepsilon 3 / \varepsilon 3$ was greatest in all of the participants, followed by $\varepsilon 3 / \varepsilon 4, \varepsilon 2 / \varepsilon 3, \varepsilon 2 / \varepsilon 4$, $\varepsilon 4 / \varepsilon 4$, and $\varepsilon 2 / \varepsilon 2$, respectively. Similarly, the carriers of $\varepsilon 3$ were greatest $(82.91 \%)$, followed by the carriers of $\varepsilon 4$ $(9.16 \%)$ and $\varepsilon 2(7.93 \%)$. Meanwhile, there were no significant differences in the APOE allele frequencies and genotypes between the males and females (all $P>0.05$ ), which was in line with the previous studies in the Asian population [19].

\section{Serum lipids according to APOE genetic polymorphism}

To preliminarily evaluate the effects of APOE on serum lipid levels, we compared the levels of serum lipids according to the APOE carriers and genotypes[20]. As shown in Table 3 , the serum TC, LDL-C, and ApoB were lower in the $\varepsilon 2$ carriers $(\varepsilon 2 / \varepsilon 2, \varepsilon 2 / \varepsilon 3$, and $\varepsilon 2 / \varepsilon 4)$ compared to the $\varepsilon 3$ carriers $(\varepsilon 3 / \varepsilon 3)$ and $\varepsilon 4$ carriers $(\varepsilon 3 /$

Table 1 General characteristics and serum lipids of the study participants

\begin{tabular}{|c|c|c|c|c|}
\hline & All $(n=1419)$ & Male $(n=795)$ & Female $(n=624)$ & $P$ value \\
\hline Age(years) & $59.18 \pm 12.53$ & $58.41 \pm 12.61$ & $59.57 \pm 12.37$ & 0.282 \\
\hline Sex, n (\%) & - & 795(56.0) & $624(44.0)$ & - \\
\hline BMI $\left(\mathrm{kg} / \mathrm{m}^{2}\right)$ & $24.96 \pm 3.34$ & $24.92 \pm 3.62$ & $25.45 \pm 4.02$ & 0.043 \\
\hline Smoking n (\%) & 258(18.18) & $252(31.7)$ & $6(0.9)$ & $<0.001$ \\
\hline $\begin{array}{l}\text { Drinking } \mathrm{n}(\%) \\
\text { No-Exercise } \mathrm{n}(\%)\end{array}$ & $\begin{array}{l}316(22.26) \\
528(37.2)\end{array}$ & $\begin{array}{l}255(32.1) \\
298(37.5)\end{array}$ & $\begin{array}{l}61(9.8) \\
230(36.8)\end{array}$ & $\begin{array}{l}<0.001 \\
0.703\end{array}$ \\
\hline $\mathrm{TC}(\mathrm{m} \mathrm{mol} / \mathrm{L})$ & $5.02 \pm 0.99$ & $4.94 \pm 0.96$ & $5.16 \pm 1.02^{*}$ & $<0.001$ \\
\hline $\mathrm{TG}(\mathrm{m} \mathrm{mol} / \mathrm{L})$ & $1.46 \pm 0.96$ & $1.56 \pm 1.09$ & $1.32 \pm 0.68^{*}$ & $<0.001$ \\
\hline HDL-C (m mol/L) & $1.35 \pm 0.38$ & $1.25 \pm 0.29$ & $1.48 \pm 0.44^{*}$ & $<0.001$ \\
\hline LDL-C (m mol/L) & $3.18 \pm 0.92$ & $3.15 \pm 0.92$ & $3.24 \pm 0.89$ & 0.073 \\
\hline $\operatorname{ApoA} 1(\mathrm{~m} \mathrm{~mol} / \mathrm{L})$ & $1.38 \pm 0.17$ & $1.35 \pm 0.15$ & $1.43 \pm 0.19^{*}$ & $<0.001$ \\
\hline ApoB (m mol/L) & $1.01 \pm 0.33$ & $1.04 \pm 0.35$ & $1.01 \pm 0.39$ & 0.227 \\
\hline A1/B & $1.37 \pm 0.56$ & $1.30 \pm 0.53$ & $1.41 \pm 0.56^{*}$ & 0.001 \\
\hline
\end{tabular}

Data are expressed as the means \pm standard deviation, except for sex, smoking, drinking, and No-exercise, which is shown as the number (\%). BMI, Body mass index, TC Total cholesterol, TG Triglyceride, HDL-C High density lipoprotein cholesterol, $L D L-C$ Low density lipoprotein cholesterol. ApoA1 apolipoproteinA1, $A p o B$ apolipoprotein B. A1/B, the ratio of ApoA1 and ApoB

$P$-value, 2-sample independent t-test, or chi-squared test as appropriate. ${ }^{*} P<0.05$, compared with males 
Table 2 Allele frequencies and distribution of APOE genotypes in middle-aged and elderly Fujian Han population

\begin{tabular}{|c|c|c|c|c|c|c|c|}
\hline \multirow{2}{*}{$\begin{array}{l}\text { Genotype } \\
\text { /Allele }\end{array}$} & \multicolumn{2}{|c|}{ All $(n=1419)$} & \multicolumn{2}{|c|}{ Male $(n=795)$} & \multicolumn{2}{|c|}{ Female $(n=624)$} & \multirow[t]{2}{*}{$P$ value } \\
\hline & No & $\%$ & No & $\%$ & No & $\%$ & \\
\hline$\varepsilon 2 / \varepsilon 2$ & 11 & 0.78 & 7 & 0.88 & 4 & 0.64 & 0.861 \\
\hline$\varepsilon 2 / \varepsilon 3$ & 176 & 12.40 & 92 & 11.57 & 84 & 13.46 & 0.342 \\
\hline$\varepsilon 2 / \varepsilon 4$ & 27 & 1.90 & 16 & 2.01 & 11 & 1.76 & 0.678 \\
\hline$\varepsilon 3 / \varepsilon 3$ & 989 & 69.70 & 563 & 70.82 & 426 & 68.27 & 0.407 \\
\hline$\varepsilon 3 / \varepsilon 4$ & 199 & 14.02 & 109 & 13.71 & 90 & 14.42 & 0.748 \\
\hline$\varepsilon 4 / \varepsilon 4$ & 17 & 1.20 & 8 & 1.01 & 9 & 1.44 & 0.787 \\
\hline$\varepsilon 2$ & 225 & 7.93 & 122 & 7.67 & 103 & 8.25 & 0.561 \\
\hline$\varepsilon 3$ & 2353 & 82.91 & 1327 & 83.46 & 1026 & 82.21 & 0.526 \\
\hline$\varepsilon 4$ & 260 & 9.16 & 141 & 8.87 & 119 & 9.54 & 0.776 \\
\hline
\end{tabular}

The $\varepsilon 2$ carriers included the genotypes $\varepsilon 2 / \varepsilon 2, \varepsilon 2 / \varepsilon 3$ and $\varepsilon 2 / \varepsilon 4$; the $\varepsilon 3$ carriers included $\varepsilon 3 / \varepsilon 3$; the $\varepsilon 4$ carriers included $\varepsilon 3 / \varepsilon 4$ and $\varepsilon 4 / \varepsilon 4$. The categorical variables were carried out by the chi-squared test

$\varepsilon 4$ and $\varepsilon 4 / \varepsilon 4$; all $P<0.05$, Fig. $1 \mathrm{~A}$ and B), and serum A1/ $\mathrm{B}$ of the $\varepsilon 2$ carriers was higher than the carriers of $\varepsilon 3$ and $\varepsilon 4$ carriers $(P<0.05$, Fig. $1 B)$.

Although the serum TC of the $\varepsilon 4$ carriers was higher than the $\varepsilon 3$ carriers intuitively, there were no significant differences in the carriers of $\varepsilon 4$ compared to the $\varepsilon 3$ carriers $(P>0.05$, Fig. $1 \mathrm{~A})$.

Based on the APOE genotype analysis, the serum TC, LDL-C, and ApoB were also lower in the $\varepsilon 2 / \varepsilon 2, \varepsilon 2 / \varepsilon 3$, and $\varepsilon 2 / \varepsilon 4$ genotypes when compared with $\varepsilon 3 / \varepsilon 3, \varepsilon 3 / \varepsilon 4$, and $\varepsilon 4 / \varepsilon 4$ (all $P<0.05$; Table 3 ; Fig. $1 C$ and $D$ ). Interestingly, the serum LDL-C and ApoB in the $\varepsilon 2 / \varepsilon 2$ genotype were lower than the $\varepsilon 2 / \varepsilon 3$ and $\varepsilon 2 / \varepsilon 4$ genotypes, while serum $A 1 / B$ in the $\varepsilon 2 / \varepsilon 2$ genotype was higher than the $\varepsilon 2 / \varepsilon 3$ and $\varepsilon 2 / \varepsilon 4$ genotypes. However, no significant differences were observed when compared to the $\varepsilon 3 / \varepsilon 4$ and $\varepsilon 4 / \varepsilon 4$ genotype (all $P>0.05$; Table 3 ; Fig. $1 \mathrm{C}$ and $\mathrm{D}$ ). These results suggest that the effects of APOE on serum lipids were gene-dependent, particularly in the $\varepsilon 2$ carriers. The influence of the APOE genotype in serum lipids was consistent with the APOE carriers.

\section{Serum lipids according to gender in different APOE carriers}

To evaluate the effects of APOE on the serum lipids in the gender, we analyzed the data of serum lipids in males and females, respectively. As shown in Table 4, in males, the serum TC, LDL-C, and ApoB of the $\varepsilon 2$ carriers were lower than those of $\varepsilon 3$ and $\varepsilon 4$. The serum $A 1 /$ $B$ in the $\varepsilon 2$ carriers was higher than the carriers of $\varepsilon 3$ and $\varepsilon 4$ (all $P<0.05$, Fig. $2 \mathrm{~A}$ ), while there were no significant differences between the $\varepsilon 3$ and $\varepsilon 4$ carriers (all $P>$ 0.05 , Fig. $2 \mathrm{~A}$ ). At the same time, in females, the serum LDL-C and ApoB of $\varepsilon 2$ carriers were lower than those of the $\varepsilon 3$ and $\varepsilon 4$ carriers. In contrast, serum $\mathrm{A} 1 / \mathrm{B}$ in the $\varepsilon 2$ carriers was higher than the carriers of $\varepsilon 3$ and $\varepsilon 4$ (all $P<$ 0.05; Fig. 2B). The serum $\mathrm{TC}$ of the $\varepsilon 4$ carriers was higher than the $\varepsilon 3$ carriers and the $\varepsilon 2$ carriers intuitively;

Table 3 The association of APOE genetic polymorphisms with serum lipids in middle-aged and elderly Fujian Han population

\begin{tabular}{|c|c|c|c|c|c|c|c|c|}
\hline Allele/ Genotype & $\mathrm{N}$ & $\begin{array}{l}\text { TC } \\
\text { (m mol/L) }\end{array}$ & $\begin{array}{l}\text { TG } \\
(\mathrm{m} \mathrm{mol} / \mathrm{L})\end{array}$ & $\begin{array}{l}\text { HDL-C } \\
\text { (m mol/L) }\end{array}$ & $\begin{array}{l}\text { LDL-C } \\
\text { (m mol/L) }\end{array}$ & $\begin{array}{l}\text { ApoA1 } \\
(\mathrm{g} / \mathrm{L})\end{array}$ & $\begin{array}{l}\text { ApoB } \\
\text { (g/L) }\end{array}$ & A1/B \\
\hline$\varepsilon 2$ carrier & 214 & $4.89 \pm 1.02^{*}$ & $1.44 \pm 0.91$ & $1.39 \pm 0.38$ & $2.84 \pm 0.91^{* *}$ & $1.42 \pm 0.19$ & $0.95 \pm 0.23^{* *}$ & $1.51 \pm 0.43^{*}$ \\
\hline$\varepsilon 3$ carrier & 989 & $5.16 \pm 0.99$ & $1.43 \pm 0.97$ & $1.35 \pm 0.34$ & $3.29 \pm 0.87$ & $1.38 \pm 0.18$ & $1.04 \pm 0.27$ & $1.36 \pm 0.38$ \\
\hline$\varepsilon 4$ carrier & 216 & $5.31 \pm 1.02$ & $1.58 \pm 1.01$ & $1.35 \pm 0.54$ & $3.31 \pm 0.98$ & $1.36 \pm 0.11$ & $1.07 \pm 0.22$ & $1.28 \pm 0.33$ \\
\hline$\varepsilon 2 / \varepsilon 2$ & 11 & $4.51 \pm 1.24^{*}$ & $2.05 \pm 1.35$ & $1.39 \pm 0.33$ & $2.20 \pm 0.69^{* * \#}$ & $1.46 \pm 0.16$ & $0.70 \pm 0.32^{*} \#$ & $2.08 \pm 0.92^{*} \#$ \\
\hline$\varepsilon 2 / \varepsilon 3$ & 176 & $4.91 \pm 1.07^{*}$ & $1.39 \pm 0.89$ & $1.40 \pm 0.38$ & $2.92 \pm 0.90^{* *}$ & $1.42 \pm 0.20$ & $0.98 \pm 0.27^{*}$ & $1.52 \pm 0.63^{*}$ \\
\hline$\varepsilon 2 / \varepsilon 4$ & 27 & $4.73 \pm 0.98^{*}$ & $1.54 \pm 0.87$ & $1.33 \pm 0.40$ & $2.83 \pm 0.79^{*}$ & $1.39 \pm 0.16$ & $1.10 \pm 0.30$ & $1.29 \pm 0.32$ \\
\hline$\varepsilon 3 / \varepsilon 3$ & 989 & $5.16 \pm 0.99$ & $1.43 \pm 0.97$ & $1.35 \pm 0.34$ & $3.29 \pm 0.87$ & $1.38 \pm 0.18$ & $1.04 \pm 0.27$ & $1.36 \pm 0.38$ \\
\hline$\varepsilon 3 / \varepsilon 4$ & 199 & $5.19 \pm 1.14$ & $1.59 \pm 1.15$ & $1.35 \pm 0.56$ & $3.27 \pm 0.99$ & $1.36 \pm 0.11$ & $1.07 \pm 0.42$ & $1.26 \pm 0.54$ \\
\hline$\varepsilon 4 / \varepsilon 4$ & 17 & $5.33 \pm 0.96$ & $1.44 \pm 0.87$ & $1.36 \pm 0.33$ & $3.38 \pm 0.78$ & $1.38 \pm 0.09$ & $1.22 \pm 0.23$ & $1.29 \pm 0.26$ \\
\hline
\end{tabular}

Data are expressed as the mean \pm SD. The $\varepsilon 2$ carriers included the genotypes $\varepsilon 2 / \varepsilon 2, \varepsilon 2 / \varepsilon 3$ and $\varepsilon 2 / \varepsilon 4$; the $\varepsilon 3$ carriers included $\varepsilon 3 / \varepsilon 3$; the $\varepsilon 4$ carriers included $\varepsilon 3 / \varepsilon 4$ and $\varepsilon 4 / \varepsilon 4$. TC Total cholesterol, TG=Triglyceride, HDL-C High density lipoprotein cholesterol, LDL-C Low density lipoprotein cholesterol. ApoA1 apolipoproteinA1, $A p o B$ apolipoprotein $B$. A1/B, the ratio of $A p o A 1$ and $A p o B$

Continuous variables were compared using unadjusted one-way ANOVA, LSD (L) post-test were performed to determine the differences in lipid parameters among different genotypes or alleles

${ }^{*} P<0.05$, ${ }^{* *} P<0.01, \varepsilon 2$ carriers VS noncarriers ( $\varepsilon 3$ carriers and $\varepsilon 4$ carriers); ${ }^{\#} P<0.05, \varepsilon 2 / \varepsilon 2$ genotype VS $\varepsilon 2 / \varepsilon 3$ and $\varepsilon 2 / \varepsilon 4$ genotype 


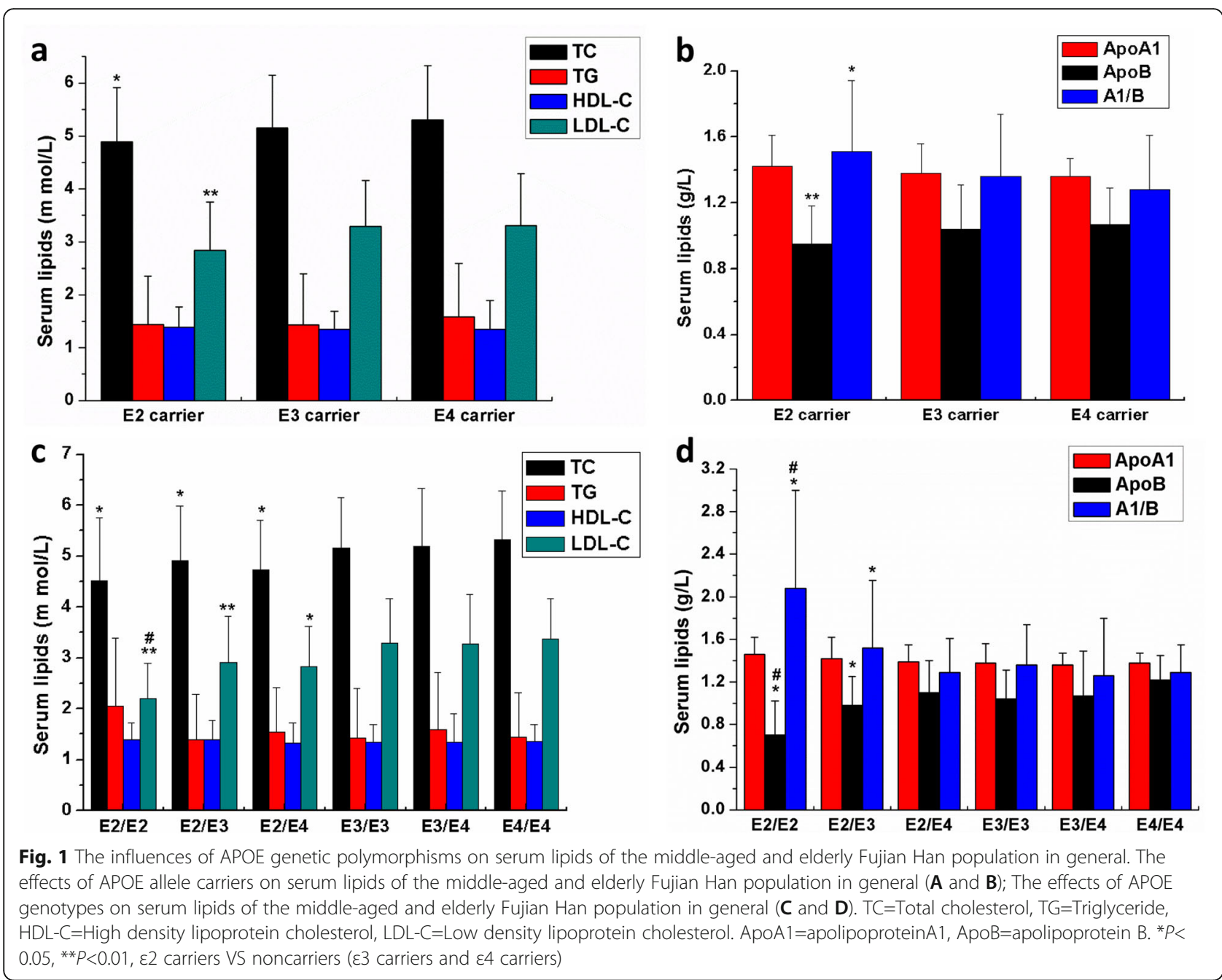

however, there were no significant differences (all $P>$ 0.05 ; Fig. 2B), which were different from the results in all subjects and the males (Fig. 2A).

We further evaluated the effects of the genotype on serum lipids. As shown in Table 4, the serum LDL-C and $A p o B$ in the $\varepsilon 2 / \varepsilon 2$ genotype were significantly lower, and the serum $\mathrm{A} 1 / \mathrm{B}$ was higher in the $\varepsilon 2 / \varepsilon 2$ genotype, both in males (Fig. 2C and D) and females (Fig. 2E and F; all $P<0.05)$ when compared with the genotype of $\varepsilon 2 /$ $\varepsilon 3$ and $\varepsilon 2 / \varepsilon 4$. However, the serum TC in the $\varepsilon 2 / \varepsilon 2$ genotype was no different compared with the genotype of $\varepsilon 2 /$ $\varepsilon 3$ and $\varepsilon 2 / \varepsilon 4$ in males $(P>0.05$, Fig. $2 C)$, while the serum TC in the $\varepsilon 2 / \varepsilon 2$ genotype was lower than the $\varepsilon 2 /$ $\varepsilon 3$ and $\varepsilon 2 / \varepsilon 4$ genotypes in females (all $P>0.05$, Fig. 2E). Additionally, no significant differences were observed in the genotype of $\varepsilon 3 / \varepsilon 4$ and $\varepsilon 4 / \varepsilon 4$ (data not shown). These data indicated that the influence of the APOE on serum lipids was gender-dependent, especially in the $\varepsilon 2$ allele. Therefore, we only analyzed the genotype of $\varepsilon 2 / \varepsilon 2$, $\varepsilon 2 /$ $\varepsilon 3$, and $\varepsilon 2 / \varepsilon 4$ in the following study.
Serum lipids according to the carriers of APOE allele, age, and gender

Based on the aforementioned results, to further evaluate the combined effects of the APOE, gender, and age on serum lipids, we divided the subjects into the middleaged group (age from 40 to 64 years old, referred to as $40+$ ) and the elderly group (age $\geq 65$ years old, referred to as 65+) for both males and females. As shown in Table 5, in 40+ males, the serum TC, LDL-C, and ApoB in the APOE $\varepsilon 2$ carriers were lower than in the carriers of $\varepsilon 3$ and $\varepsilon 4$, and serum $A 1 / B$ in the $\varepsilon 2$ carriers was higher than the noncarriers (all $P<0.05$; Fig. $3 \mathrm{~A}$ and $\mathrm{B}$ ). However, the serum HDL-C and ApoA1 in the $\varepsilon 4$ carriers were lower than the $\varepsilon 2$ and $\varepsilon 3$ carriers (all $P<0.05$; Fig. $3 \mathrm{~A}$ and B) in $40+$ males, which was not observed in whole males and all participants. Then, in the $65+$ males, the serum LDL-C and ApoB in the $\varepsilon 2$ carriers were lower than in the noncarriers, and serum A1/B was higher in the $\varepsilon 2$ carriers (all $P<0.05$, Fig. $3 C$ and $D$ ). However, the serum $\mathrm{TC}$ of the $\varepsilon 2$ carriers showed no 
Table 4 The influence of Alleles of APOE and sex in serum lipid profile in middle-aged and elderly Fujian Han population

\begin{tabular}{|c|c|c|c|c|c|c|c|c|}
\hline \multirow[t]{2}{*}{ Allele } & \multicolumn{3}{|c|}{ Male $(n=795)$} & \multirow[t]{2}{*}{$P$ value } & \multicolumn{3}{|c|}{ Female $(n=624)$} & \multirow[t]{2}{*}{$P$ value } \\
\hline & $\varepsilon 2$ (115) & $\varepsilon 3(563)$ & $\varepsilon 4(117)$ & & $\varepsilon 2(99)$ & $\varepsilon 3(426)$ & $\varepsilon 4(99)$ & \\
\hline $\mathrm{TC}$ & $4.69 \pm 1.01^{*}$ & $5.03 \pm 0.94$ & $5.07 \pm 0.98$ & 0.030 & $5.14 \pm 1.01$ & $5.22 \pm 0.99$ & $5.53 \pm 0.97$ & 0.172 \\
\hline TG & $1.62 \pm 1.05$ & $1.55 \pm 1.04$ & $1.63 \pm 1.08$ & 0.853 & $1.18 \pm 0.57$ & $1.23 \pm 0.65$ & $1.45 \pm 0.70$ & 0.114 \\
\hline HDL-C & $1.25 \pm 0.28$ & $1.27 \pm 0.30$ & $1.18 \pm 0.24$ & 0.182 & $1.60 \pm 0.41$ & $1.48 \pm 0.35$ & $1.53 \pm 0.71$ & 0.363 \\
\hline LDL-C & $2.70 \pm 0.92^{* *}$ & $3.27 \pm 0.89$ & $3.29 \pm 0.86$ & $<0.001$ & $2.98 \pm 0.86^{*}$ & $3.29 \pm 0.84$ & $3.35 \pm 0.94$ & 0.037 \\
\hline ApoA1 & $1.37 \pm 0.14$ & $1.35 \pm 0.15$ & $1.33 \pm 0.10$ & 0.278 & $1.48 \pm 0.24$ & $1.43 \pm 0.20$ & $1.41 \pm 0.11$ & 0.206 \\
\hline ApoB & $0.93 \pm 0.19^{*}$ & $1.04 \pm 0.23$ & $1.05 \pm 0.23$ & 0.024 & $0.94 \pm 0.24^{*}$ & $0.99 \pm 0.28$ & $1.09 \pm 0.29$ & 0.015 \\
\hline A1/B & $1.58 \pm 0.37^{*}$ & $1.37 \pm 0.52$ & $1.30 \pm 0.39$ & 0.038 & $1.72 \pm 0.58^{*}$ & $1.54 \pm 0.53$ & $1.36 \pm 0.45$ & 0.029 \\
\hline Genotype & $\varepsilon 2 / \varepsilon 2(7)$ & $\varepsilon 2 / \varepsilon 3(92)$ & $\varepsilon 2 / \varepsilon 4(16)$ & & $\varepsilon 2 / \varepsilon 2(4)$ & $\varepsilon 2 / \varepsilon 3(84)$ & $\varepsilon 2 / \varepsilon 4(11)$ & \\
\hline TC & $4.95 \pm 1.09$ & $4.70 \pm 1.07$ & $4.55 \pm 0.63$ & 0.315 & $3.64 \pm 0.62$ & $5.19 \pm 1.02^{\#}$ & $5.08 \pm 0.91^{\#}$ & 0.038 \\
\hline TG & $1.67 \pm 1.31$ & $1.59 \pm 1.04$ & $1.55 \pm 0.92$ & 0.202 & $0.94 \pm 0.31$ & $1.14 \pm 0.53$ & $1.52 \pm 0.90$ & 0.156 \\
\hline HDL-C & $1.31 \pm 0.36$ & $1.26 \pm 0.26$ & $1.22 \pm 0.37$ & 0.436 & $1.42 \pm 0.31$ & $1.61 \pm 0.42$ & $1.56 \pm 0.39$ & 0.765 \\
\hline LDL-C & $1.77 \pm 0.33$ & $2.81 \pm 0.94^{\# \#}$ & $2.67 \pm 0.49^{\#}$ & $<0.001$ & $2.95 \pm 0.64$ & $3.07 \pm 0.84^{\#}$ & $3.19 \pm 0.81^{\#}$ & 0.036 \\
\hline ApoA1 & $1.39 \pm 0.12$ & $1.38 \pm 0.15$ & $1.32 \pm 0.11$ & 0.590 & $1.55 \pm 0.14$ & $1.46 \pm 0.25$ & $1.54 \pm 0.19$ & 0.491 \\
\hline ApoB & $0.76 \pm 0.11$ & $0.98 \pm 0.29^{\#}$ & $1.14 \pm 0.31^{\#}$ & 0.038 & $0.79 \pm 0.50$ & $0.97 \pm 0.29^{\# \#}$ & $1.02 \pm 0.29^{\#}$ & 0.002 \\
\hline A1/B & $2.11 \pm 0.33$ & $1.49 \pm 0.67^{\#}$ & $1.16 \pm 0.37^{\# \#}$ & 0.043 & $2.12 \pm 0.68$ & $1.72 \pm 0.69^{\# \#}$ & $1.71 \pm 0.52^{\# \#}$ & $<0.001$ \\
\hline
\end{tabular}

Data are expressed as the mean \pm SD. TC Total cholesterol, TG Triglyceride, HDL-C High density lipoprotein cholesterol, $L D L-C$ Low density lipoprotein cholesterol. ApoA1 apolipoproteinA1, ApoB apolipoprotein B. A1/B, the ratio of ApoA1 and ApoB. Values were compared using unadjusted one-way ANOVA, LSD (L) post-test were performed to compare the differences in lipid parameters among different carriers

${ }^{*} P<0.05$, ${ }^{* *} P<0.01, \varepsilon 2$ carriers VS noncarriers ( $\varepsilon 3$ carriers and $\varepsilon 4$ carriers); ${ }^{\#} P<0.05,{ }^{\# \#} P<0.01$, compared with the $\varepsilon 2 / \varepsilon 2$ genotype

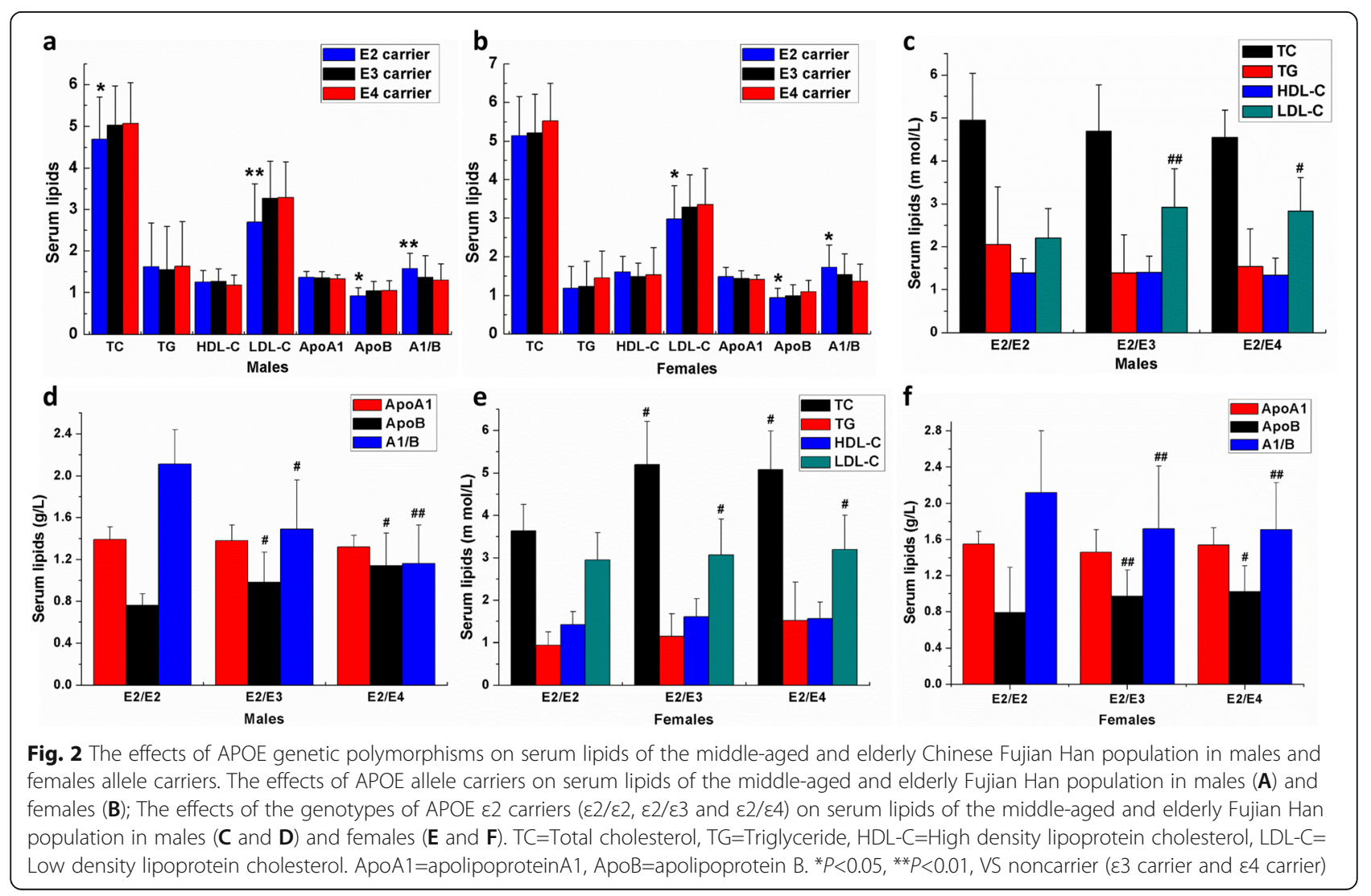


Table 5 The effects of APOE, age, and sex in serum lipid profile in middle-aged and elderly Fujian Han population

\begin{tabular}{|c|c|c|c|c|c|c|c|c|}
\hline \multirow{2}{*}{$\begin{array}{l}\text { serum } \\
\text { lipids }\end{array}$} & \multicolumn{4}{|l|}{ Male (795) } & \multicolumn{4}{|c|}{ Female (624) } \\
\hline & all & $\varepsilon 2$ (115) & $\varepsilon 3(563)$ & $\varepsilon 4(117)$ & all & ع2 (99) & $\varepsilon 3(426)$ & $\varepsilon 4(99)$ \\
\hline $40-64$ & $N=481$ & $N=65$ & $N=350$ & $N=66$ & $N=355$ & $N=54$ & $N=244$ & $N=57$ \\
\hline TC & $5.09 \pm 0.93$ & $4.85 \pm 0.86^{*}$ & $5.14 \pm 0.92$ & $5.06 \pm 1.02$ & $5.20 \pm 0.99$ & $5.12 \pm 0.97$ & $5.19 \pm 1.02$ & $5.33 \pm 0.95$ \\
\hline TG & $1.75 \pm 1.25$ & $1.78 \pm 1.13$ & $1.72 \pm 1.20$ & $1.93 \pm 1.33$ & $1.19 \pm 0.65$ & $1.14 \pm 0.57$ & $1.16 \pm 0.71$ & $1.34 \pm 0.45$ \\
\hline HDL-C & $1.23 \pm 0.27$ & $1.25 \pm 0.29$ & $1.25 \pm 0.27$ & $1.14 \pm 0.22^{\#}$ & $1.52 \pm 0.36$ & $1.65 \pm 0.42^{*}$ & $1.49 \pm 0.33$ & $1.53 \pm 0.41$ \\
\hline LDL-C & $3.31 \pm 0.91$ & $2.84 \pm 0.74^{*}$ & $3.41 \pm 0.91$ & $3.26 \pm 0.94$ & $3.23 \pm 0.86$ & $3.01 \pm 0.78$ & $3.25 \pm 0.87$ & $3.34 \pm 0.88$ \\
\hline ApoA1 & $1.35 \pm 0.15$ & $1.38 \pm 0.17$ & $1.35 \pm 0.15$ & $1.30 \pm 0.10^{\#}$ & $1.44 \pm 0.20$ & $1.52 \pm 0.26^{*}$ & $1.42 \pm 0.21$ & $1.43 \pm 0.11$ \\
\hline ApoB & $1.12 \pm 0.38$ & $1.01 \pm 0.24^{*}$ & $1.12 \pm 0.34$ & $1.25 \pm 0.61$ & $1.05 \pm 0.28$ & $0.98 \pm 0.28$ & $1.04 \pm 0.28$ & $1.07 \pm 0.28$ \\
\hline $\mathrm{A} 1 / \mathrm{B}$ & $1.29 \pm 0.46$ & $1.39 \pm 0.46^{*}$ & $1.28 \pm 0.43$ & $1.27 \pm 0.64$ & $1.44 \pm 0.54$ & $1.66 \pm 0.46^{*}$ & $1.44 \pm 0.52$ & $1.32 \pm 0.48$ \\
\hline $65+$ & $N=314$ & $N=50$ & $N=213$ & $N=51$ & $N=269$ & $N=45$ & $N=182$ & $N=42$ \\
\hline $\mathrm{TC}$ & $4.63 \pm 0.95$ & $4.35 \pm 1.16$ & $4.71 \pm 0.91$ & $4.60 \pm 0.86$ & $5.30 \pm 1.11$ & $5.17 \pm 1.12$ & $5.32 \pm 0.95$ & $5.33 \pm 1.02$ \\
\hline TG & $1.22 \pm 0.83$ & $1.40 \pm 0.83$ & $1.19 \pm 0.91$ & $1.15 \pm 0.85$ & $1.46 \pm 0.72$ & $1.24 \pm 0.59$ & $1.38 \pm 0.53$ & $1.82 \pm 0.84^{\#}$ \\
\hline HDL-C & $1.29 \pm 0.33$ & $1.23 \pm 0.27$ & $1.31 \pm 0.35$ & $1.27 \pm 0.24$ & $1.48 \pm 0.59$ & $1.49 \pm 0.38$ & $1.47 \pm 0.42$ & $1.53 \pm 0.61$ \\
\hline LDL-C & $2.90 \pm 0.88$ & $2.36 \pm 1.17^{* *}$ & $2.99 \pm 0.79$ & $3.09 \pm 0.85$ & $3.34 \pm 0.98$ & $3.09 \pm 0.94$ & $3.39 \pm 0.77$ & $3.38 \pm 0.88$ \\
\hline ApoA1 & $1.34 \pm 0.12$ & $1.35 \pm 0.08$ & $1.33 \pm 0.14$ & $1.36 \pm 0.09$ & $1.41 \pm 0.18$ & $1.40 \pm 0.15$ & $1.43 \pm 0.19$ & $1.37 \pm 0.12$ \\
\hline ApoB & $1.19 \pm 0.31$ & $1.08 \pm 0.38^{*}$ & $1.19 \pm 0.29$ & $1.26 \pm 0.25$ & $1.22 \pm 0.29$ & $1.17 \pm 0.41$ & $1.22 \pm 0.25$ & $1.27 \pm 0.32$ \\
\hline$A 1 / B$ & $1.03 \pm 0.68$ & $1.26 \pm 0.54^{*}$ & $1.04 \pm 0.64$ & $1.02 \pm 0.46$ & $1.11 \pm 0.59$ & $1.11 \pm 0.45$ & $1.12 \pm 0.50$ & $1.08 \pm 0.38$ \\
\hline
\end{tabular}

Data are expressed as the mean \pm SD.TC Total cholesterol, TG Triglyceride, HDL-C High density lipoprotein cholesterol, $L D L-C$ Low density lipoprotein cholesterol. ApoA1 apolipoprotein A, $A p o B$ apolipoprotein B. A1/B, the ratio of ApoA1 and ApoB. Values were compared using unadjusted one-way ANOVA, LSD (L) post-test were performed to determine the differences in lipid parameters among different allele carriers

${ }^{*} P<0.05,{ }^{*} P<0.01, \varepsilon 2$ carriers VS noncarriers ( $\varepsilon 3$ carriers and $\varepsilon 4$ carriers); ${ }^{\#} P<0.05, \varepsilon 4$ carriers VS noncarriers ( $\varepsilon 3$ carriers and $\varepsilon 2$ carriers)

significant differences compared with the $\varepsilon 3$ carriers $(P>0.05$, Fig. 3C), which was inconsistent with the $40+$ males and the whole males.

Meanwhile, in $40+$ females, the serum HDL-C and ApoA1 of the $\varepsilon 2$ carriers were higher than the noncarriers (all $P<0.05$; Fig. $4 \mathrm{~A}$ and $\mathrm{B}$ ). Then, in $65+$ females, only the serum TG in the $\varepsilon 4$ carriers was higher than the noncarriers $(P<0.05$; Fig. $4 \mathrm{C}$ and $\mathrm{D})$. In contrast, no significant difference was found in the serum TC, LDL$\mathrm{C}$, and $\mathrm{ApoB}$ among different APOE allele carriers in $40+$ females and 65+ females (all $P>0.05$; Fig. $4 \mathrm{C}$ and D). These results indicated that the effects of the APOE allele carriers on serum lipids were also in an age- and gender-dependent manner both in males and females.

\section{The association of APOE allele carrier status and at-risk levels of dyslipidemia}

To estimate the associations between the APOE allele carrier status and the at-risk levels of dyslipidemia in the middle-aged and elderly population, we used the logistic regression analysis to determine the odds ratios (OR), which reveal the at-risk levels of dyslipidemia. The diagnosis of dyslipidemia was based on the Guidelines for the Prevention and Treatment of Dyslipidemia in Chinese Adults (revised 2016) [21].

As shown in Table 6 , for $40+$ males and $65+$ males, after adjusting for BMI, education, physical activity, smoking, and alcohol drinking, the APOE $\varepsilon 2$ carriers were less likely to have at-risk levels of high LDL-C ( $\geq$ $3.4 \mathrm{~m} \mathrm{~mol} / \mathrm{L})$ and the value of OR was $0.165(95 \% \mathrm{CI}=$ $0.061-0.444, P=0.001)$ and $0.204(95 \% \mathrm{CI}=0.060$ $0.916, P=0.034)$, respectively. Later, in $40+$ females, the $\varepsilon 2$ carriers were less likely to have at-risk levels of low HDL-C $(<1.0 \mathrm{~m} \mathrm{~mol} / \mathrm{L})$, while the others had no significant differences. Particularly in $65+$ females, the $\varepsilon 4$ carriers were more likely to have at-risk levels of high TG $(\geq 1.7 \mathrm{~m} \mathrm{~mol} / \mathrm{L})$. The value of OR was $2.937(95 \% \mathrm{CI}=$ 1.026-8.464, $P=0.046)$.

\section{Discussion}

This study focused on the combined effects of APOE genetic polymorphism, age, and sex on serum lipids during aging. Our results showed that the influences of APOE genetic polymorphisms on the serum lipid profiles during aging were both gender- and age-dependent. The carrier of APOE $\varepsilon 2$ could be a protective factor of dyslipidemia, while APOE $\varepsilon 4$ carriers might be closely associated with the high TG, particularly in elderly females.

First, our results showed that the genotypes and allelic distribution of APOE in the middle-aged and elderly Chinese Fujian Han population were no different compared with the previously reported results in the Asian population $[19,22]$. Then, we preliminarily evaluated the influences of the APOE genetic polymorphisms on serum lipids. Our results indicated that the serum TC, 

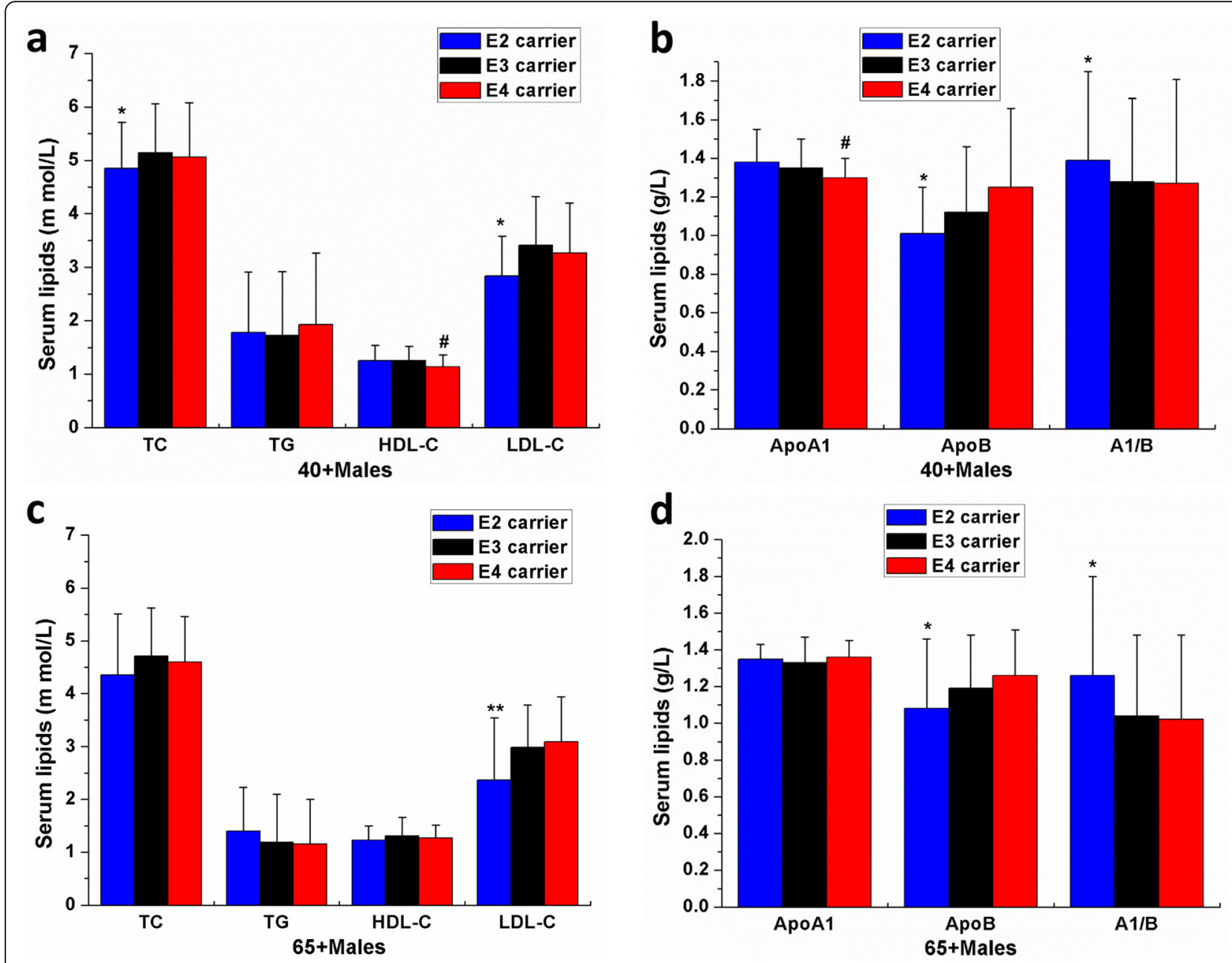

Fig. 3 The effects of APOE allele carriers and age on serum lipids in the middle-aged (40+) and elderly (65+) males of Fujian Han population. The influence of APOE allele carriers and age on serum TC, TG, HDL-C and LDL-C (A) and serum ApoA1, ApoB and A1/B (B) in the 40+ males; The influence of APOE allele carriers and age on serum TC, TG, HDL-C and LDL-C (C) and serum ApoA1, ApoB and A1/B (D) in the 65+ males. TC= Total cholesterol, TG=Triglyceride, HDL-C=High density lipoprotein cholesterol, LDL-C=Low density lipoprotein cholesterol. ApoA1= apolipoproteinA1, ApoB=apolipoprotein $B .{ }^{*} P<0.05,{ }^{*} P<0.01$, $\varepsilon 2$ carriers VS noncarriers ( $\varepsilon 3$ carriers sand $\varepsilon 4$ carriers); ${ }^{\#} P<0.05, \varepsilon 4$ carriers VS noncarriers ( $\varepsilon 3$ carriers and $\varepsilon 2$ carriers)

LDL-C, and ApoB of the APOE $\varepsilon 2$ carriers were lower than the $\varepsilon 3$ carriers. At the same time, there were no significant differences in the $\varepsilon 4$ carriers compared with the $\varepsilon 3$ carriers.

Meanwhile, the serum TC, LDL-C, and ApoB in the genotypes of $\varepsilon 2 / \varepsilon 2, \varepsilon 2 / \varepsilon 3$, and $\varepsilon 2 / \varepsilon 4$ were also lower when compared with $\varepsilon 3 / \varepsilon 3, \varepsilon 3 / \varepsilon 4$, and $\varepsilon 4 / \varepsilon 4$. More interesting, the serum LDL-C and ApoB in the $\varepsilon 2 / \varepsilon 2$ genotype were lower, while serum $\mathrm{A} 1 / \mathrm{B}$ in the $\varepsilon 2 / \varepsilon 2$ genotype was higher compared with the $\varepsilon 2 / \varepsilon 3$ and $\varepsilon 2 / \varepsilon 4$ genotypes. However, no significant differences were observed between the $\varepsilon 3 / \varepsilon 4$ and $\varepsilon 4 / \varepsilon 4$ genotypes.

The gender differences in serum lipids during aging have been reported in many pieces of literature [12]. The present study showed that the serum TC, LDL-C, and $A$ poB of the $\varepsilon 2$ carriers were lower than that of the $\varepsilon 3$ and $\varepsilon 4$ carriers in males. In females, the serum LDL$\mathrm{C}$ and $\mathrm{ApoB}$ in the $\varepsilon 2$ carriers were also lower than the carriers of $\varepsilon 3$ and $\varepsilon 4$, while the serum TC showed no significant differences. Then, the effects of the genotype on serum lipids were also evaluated. The significant differences were only observed in the genotype of $\varepsilon 2$ carriers. The serum LDL-C and ApoB in the $\varepsilon 2 / \varepsilon 2$ genotype were significantly lower, and the serum A1/B was higher in the $\varepsilon 2 / \varepsilon 2$ genotype, both in males and females. While the serum $\mathrm{TC}$ in the $\varepsilon 2 / \varepsilon 2$ genotype was lower than the $\varepsilon 2 / \varepsilon 3$ and $\varepsilon 2 / \varepsilon 4$ genotypes in females. These data indicated that the influence of the APOE on serum lipids was gender-dependent, particularly in the $\varepsilon 2$ allele.

Next, we observed the differences in serum lipids between middle-aged (40+) and the elderly (65+) males 

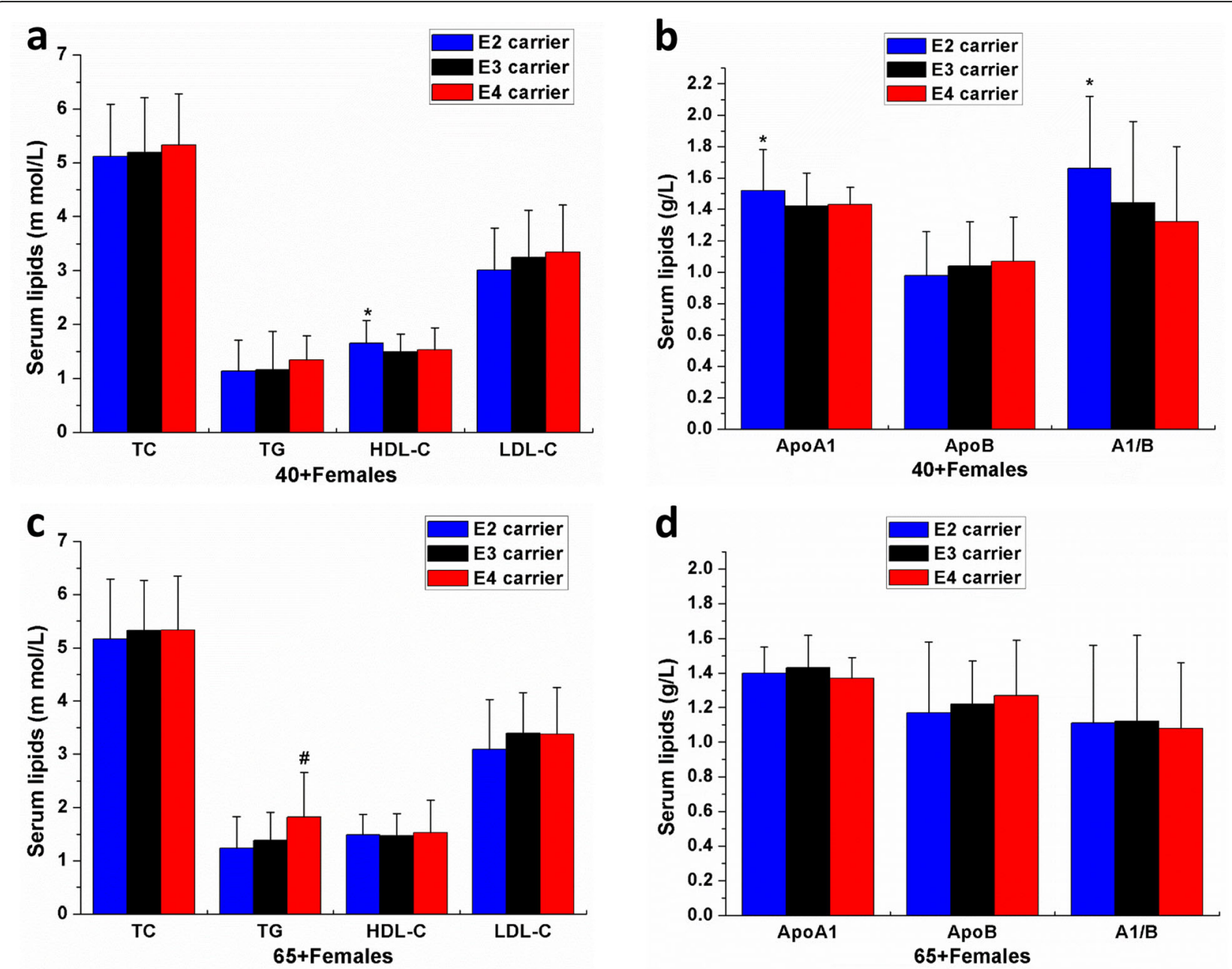

Fig. 4 The effects of APOE allele carriers and age on serum lipids in the middle-aged (40+) and elderly (65+) females of Fujian Han population. The influence of APOE allele carriers and age on serum TC, TG, HDL-C and LDL-C (A) and serum ApoA1, ApoB and A1/B (B) in the 40+ females; The influence of APOE allele carriers and age on serum TC, TG, HDL-C and LDL-C (C) and serum ApoA1, ApoB and A1/B (D) in the $65+$ females. TC=Total cholesterol, TG=Triglyceride, HDL-C=High density lipoprotein cholesterol, LDL-C=Low density lipoprotein cholesterol. ApoA $1=$ apolipoprotein $A 1, A p o B=$ apolipoprotein $B .{ }^{*} P<0.05,{ }^{* *} P<0.01, \varepsilon 2$ carriers VS noncarriers ( $\varepsilon 3$ carriers and $\varepsilon 4$ carriers); ${ }^{\#} P<0.05, \varepsilon 4$ carriers VS noncarriers ( $\varepsilon 3$ carriers and $\varepsilon 2$ carriers)

and females, respectively. The serum LDL-C and ApoB in $\varepsilon 2$ carriers were significantly lower than the noncarriers, both in the $40+$ males and $65+$ males. However, the serum HDL-C of ApoA1 for 40+ males in $\varepsilon 4$ carriers was substantially lower than the $\varepsilon 2$ and $\varepsilon 3$ carriers, and the serum TC for $65+$ males in $\varepsilon 2$ carriers had no significant differences compared to noncarriers. Meanwhile, the serum HDL-C and ApoA1 for $40+$ females in the $\varepsilon 2$ carriers were higher than those of $\varepsilon 3$ and $\varepsilon 4$. Moreover, in $65+$ females, the serum TG in the $\varepsilon 4$ carriers was higher than in the noncarriers, while the other serum lipids showed no significant differences. These results indicated that the effects of the APOE allele carriers on serum lipids were gender- and age-dependent for the middle-aged (40+) and the elderly (65+) populations.
Finally, according to the 2016 China dyslipidemia criteria, using the logistic regression models, we found that, for $40+$ males and $65+$ males, the APOE $\varepsilon 2$ carriers were less likely to have at-risk levels of high LDL-C ( $\geq 3.4 \mathrm{~m}$ $\mathrm{mol} / \mathrm{L}$ ). Meanwhile, in $40+$ females, the carriers of APOE $\varepsilon 2$ were less likely to have at-risk levels of low HDL-C (< $1.0 \mathrm{~m} \mathrm{~mol} / \mathrm{L}$ ). Interestingly, in $65+$ females, the carriers of APOE $\varepsilon 4$ were more likely to have at-risk levels of high TG $(\geq 1.7 \mathrm{~m} \mathrm{~mol} / \mathrm{L})$.

The role of the APOE genetic polymorphism in the serum LDL-C in the general population has been reported in many studies, and the APOE $\varepsilon 2$ demonstrated lower serum LDL-C levels [23-25]. In this study, the serum LDL-C and ApoB in the $\varepsilon 2$ carriers were significantly lower than non- $\varepsilon 2$ carriers in middle-aged $(40+)$ 
Table 6 Odds ratios from logistic regression models predicting at-risk levels of serum lipids by APOE $\varepsilon 2$ and $\varepsilon 4$ carriers in middleaged (40+) and elderly (60+) males or females

\begin{tabular}{|c|c|c|c|c|c|}
\hline & \multirow{2}{*}{$\begin{array}{l}\text { Serum } \\
\text { Outcome }\end{array}$} & \multicolumn{2}{|c|}{$\varepsilon 2$ carrier } & \multicolumn{2}{|c|}{$\varepsilon 4$ carrier } \\
\hline & & Pvalue & OR $(95 \% \mathrm{Cl})$ & Pvalue & OR $(95 \% \mathrm{Cl})$ \\
\hline Male & $\mathrm{TC}(\geq 5.2)$ & 0.080 & $0.494(0.224,1.088)$ & 0.701 & $0.824(0.411,1.817)$ \\
\hline \multirow[t]{3}{*}{$40+$} & TG $(\geq 1.7)$ & 0.806 & $0.909(0.425,1.945)$ & 0.431 & $0.726(0.327,1.612)$ \\
\hline & $\operatorname{HDLC}(<1.0)$ & 0.878 & $1.078(0.414,2.805)$ & 0.065 & $0.466(0.207,1.057)$ \\
\hline & LDL-C ( $\geq 3.4)$ & $0.001^{* *}$ & $0.165(0.061,0.444)$ & 0.112 & $0.539(0.252,1.155)$ \\
\hline \multirow[t]{4}{*}{$65+$} & $\mathrm{TC}(\geq 5.2)$ & 0.608 & $0.730(0.220,2.430)$ & 0.702 & $0.806(0.267,2.434)$ \\
\hline & TG $(\geq 1.7)$ & 0.072 & $3.556(0.894,14.135)$ & 0.346 & $2.113(0.217,5.711)$ \\
\hline & $\operatorname{HDLC}(<1.0)$ & 0.210 & $3.303(0.471,10.723)$ & 0.658 & $1.357(0.445,10.020)$ \\
\hline & LDL-C $(\geq 3.4)$ & $0.034^{*}$ & $0.204(0.060,0.916)$ & 0.953 & $0.969(0.339,2.768)$ \\
\hline Female & $\mathrm{TC}(\geq 5.2)$ & 0.985 & $1.009(0.424,2.401)$ & 0.664 & $0.836(0.371,1.880)$ \\
\hline \multirow[t]{3}{*}{$40+$} & TG $(\geq 1.7)$ & 0.374 & $0.386(0.048,3.139)$ & 0.290 & $1.855(0.591,5.822)$ \\
\hline & HDLC $(<1.0)$ & 0.998 & O(----, ----) & 0.601 & $0.523(0.046,5.965)$ \\
\hline & LDL-C ( $\geq 3.4)$ & 0.109 & $0.598(0.339,1.551)$ & 0.746 & $1.143(0.509,2.564)$ \\
\hline \multirow[t]{4}{*}{$65+$} & $\mathrm{TC}(\geq 5.2)$ & 0.954 & $1.037(0.297,3.616)$ & 0.944 & $1.036(0.373,2.886)$ \\
\hline & TG $(\geq 1.7)$ & 0.602 & $0.646(0.125,3.333)$ & $0.046^{*}$ & $2.937(1.026,8.464)$ \\
\hline & $\operatorname{HDLC}(<1.0)$ & 0.203 & $0.288(0.043,1.954)$ & 0.195 & $0.327(0.060,1.774)$ \\
\hline & LDL-C ( $\geq 3.4)$ & 0.668 & $0.750(0.201,2.796)$ & 0.698 & $1.227(0.437,3.448)$ \\
\hline
\end{tabular}

$O R$ odds ratio; $\mathrm{Cl}$ confidence interval. The confounding factors including age, BMl, education, smoking, alcohol drinking, and physical activity were critically adjusted. TC Total cholesterol, TG Triglyceride, HDL-C High density lipoprotein cholesterol, LDL-C Low density lipoprotein cholesterol. ApoA1 apolipoproteinA1, $A p o B$ apolipoprotein B

The diagnostic criteria for dyslipidemia: high TC ( $\geq 5.2 \mathrm{~m} \mathrm{~mol} / \mathrm{L})$, high TG ( $\geq 1.7 \mathrm{~m} \mathrm{~mol} / \mathrm{L})$, high LDL-C ( $\geq 3.4 \mathrm{~m} \mathrm{~mol} / \mathrm{L})$, and low HDL-C $(<1.0 \mathrm{~m} \mathrm{~mol} / \mathrm{L})$ ${ }^{*} P<0.05,{ }^{* *} P<0.01$, VS $\varepsilon 3$ carriers

and elderly $(65+)$ males. Still, there were no significant differences in middle-aged (40+) females. This result was consistent with the aforementioned previous studies $[9,26]$. The association of the $\varepsilon 4$ carriers with the serum TC is inconsistent at present. This study is consistent with those studies that observed no significant difference in the $\varepsilon 4$ carriers $[11,22]$. While the other reported that serum TC in the $\varepsilon 4$ carriers was higher compared to noncarriers [27]. The inconsistency may be attributed to differences in the study population, race, geographical area, and study size. The serum TC in the $\varepsilon 2$ carriers was lower than noncarriers in $40+$ males. However, there were no differences in $65+$ males and $40+$ females. The concentrations of serum HDL-C and ApoA1 of $\varepsilon 4$ carriers were lower than non- $\varepsilon 4$ carriers in $40+$ males, while in $40+$ females the serum HDL-C and ApoA1 were higher in the $\varepsilon 2$ carriers compared to the noncarriers.

Notably, the serum TG in the $\varepsilon 4$ carriers was significantly higher than the noncarriers $(\varepsilon 2$ and $\varepsilon 3)$ in elderly $(65+)$ females, which was partly consistent with the other study [28]. The differences between various studies might be related to the study population, such as race and dietary habits. Significantly, serum TG is closely associated with diet [29]. The Fujian Province is located on the southeast coast of China. Residents of the Fujian Province love to eat seafood and aquatic products, particularly soup, referred to as "Fujian cuisine," characterized by low salt and low fat. Meanwhile, most of them have a habit of drinking tea.

The molecular mechanisms of difference of serum lipids among APOE carriers remain unclear; however, they might be related to the structural differences among ApoE2, ApoE3, and ApoE4 [25]. The APOE $\varepsilon 2$ carriers display low LDL-C levels that may be associated with the defective binding of ApoE2 to LDL receptors (LDLR) [30]. Studies have suggested the ApoE3 and ApoE4 bind to the LDLR with similar affinity, but the binding of ApoE2 to LDLR is poor, which decreases the hepatic uptake of VLDL [31]. As a consequence, APOE $\varepsilon 2$ carriers have lower levels of LDL-C. However, the exaggerated TG response in APOE $\varepsilon 4$ carriers may be related to the different lipoprotein distributions of ApoE3 and ApoE4 in serum, thereby affecting the metabolic rate of ApoEcontaining lipoproteins [32]. Studies have shown that compared with ApoE3, ApoE4 binds better to VLDL because of its higher lipid affinity [33]. After secretion from the liver into the plasma, TG in VLDL is hydrolyzed by lipoprotein lipase, leading to the creation of intermediate density lipoprotein (IDL); however, excess of ApoE4 on the surface of VLDL particles can impair their lipolysis, which elevates plasma TG levels 
[34]. Further research will be needed to discover the exact mechanisms of the combined effects of APOE, sex, and age on serum lipids.

\section{Study strength and limitations}

To our knowledge, this is the first population-based association study to explore the combined effects of APOE genetic polymorphisms, gender, and age on serum lipids in the middle-aged and elderly Chinese Fujian Han population. Our results could provide robust evidence for preventing and managing dyslipidemia in China's middle-aged and elderly population, particularly for individualized prevention based on the APOE genotypes.

However, some limitations should also be noted. First, the variations from the study of individuals should be considered. Many factors could contribute to the serum lipid levels, particularly dietary factors, lifestyle, and random factors [35]. Meanwhile, the serum hormonal levels are different in the middle-aged and elderly population, particularly for females. When we estimate the effects of gender on serum lipids, serum hormonal levels should be considered. If we can provide the serum hormonal levels in the current study, the evidence of gender on serum lipids would be more powerful. Moreover, the original aim of this study was to identify the risk factors or individuals based on the APOE genotypes. However, the final data showed the carrier of APOE $\varepsilon 2$ could be a protective factor of dyslipidemia, while only in the elderly $(65+)$ females, the APOE $\varepsilon 4$ carriers might be a risk factor for high $\mathrm{TG}$, which might limit the innovation of this study to a certain extent. Finally, our study was performed in a single center, which would limit the ability to draw major conclusions on all populations.

\section{Conclusions}

In conclusion, the effects of the genetic polymorphisms of APOE on the serum lipids were both gender- and age-dependent in the middle-aged and elderly Chinese Fujian Han population. Our results could provide useful evidence for preventing and managing dyslipidemia via personalized strategies in China's middle-aged and elderly population, particularly based on the APOE genotype.

\section{Data sharing statement}

No additional data are available.

\section{Authors' contributions}

XFL designed the study, analyzed the data, and wrote the manuscript. MJT collected the clinical data, WQZ and BY performed the biochemistry analysis. QWL and KNF carried out the PCR and determined the genotype of APOE. QSO participated in the study's design, reviewed the article, and provided funding to support the study. All authors read and approved the final manuscript.

\section{Funding}

The study was supported in part by the grants from the National Natural Science Foundation of China (No.81802088), the Joint Funds for the Innovation of Science and Technology, Fujian Province (No.2018Y9080).
Availability of data and materials

Not applicable.

\section{Declarations}

\section{Ethics approval and consent to participate}

The study was approved by the Research ethics committees of the First Affiliated Hospital of Fujian Medical University and the written informed consent was signed by all subjects following the Declaration of Helsinki before the study.

\section{Consent for publication}

Not applicable.

\section{Competing interests}

All authors declare that there are no competing interests.

\section{Author details}

${ }^{1}$ Department of Laboratory Medicine, the First Affiliated Hospital of Fujian Medical University, 20 Chazhong Road, 350005 Fuzhou, China. ${ }^{2}$ Fujian Key Laboratory of Laboratory Medicine, No.20 Chazhong Road, 20 Chazhong Road, 350005 Fuzhou, China. ${ }^{3}$ Gene Diagnostic Laboratory, the First Affiliated Hospital of Fujian Medical University, 350005 Fuzhou, China.

Received: 2 August 2021 Accepted: 25 October 2021

Published online: 08 November 2021

\section{References}

1. Li X, Cao X, Guo M, Xie M, Liu X. Trends and risk factors of mortality and disability adjusted life years for chronic respiratory diseases from 1990 to 2017: systematic analysis for the Global Burden of Disease Study 2017. Bmj. 2020;368:m234

2. GBD 2016 Disease and Injury Incidence and Prevalence Collaborators. Global, regional, and national incidence, prevalence, and years lived with disability for 328 diseases and injuries for 195 countries, 1990-2016: a systematic analysis for the Global Burden of Disease Study 2016. Lancet. 2017;390:1211-59.

3. Pan L, Yang Z, Wu Y, Yin RX, Liao Y, Wang J, Gao B, Zhang L. The prevalence, awareness, treatment and control of dyslipidemia among adults in China. Atherosclerosis. 2016;248:2-9.

4. Opoku S, Gan Y, Fu W, Chen D, Addo-Yobo E, Trofimovitch D, Yue W, Yan F, Wang Z, Lu Z. Prevalence and risk factors for dyslipidemia among adults in rural and urban China: findings from the China National Stroke Screening and prevention project (CNSSPP). BMC Public Health. 2019;19:1500.

5. Woo JG, Morrison JA, Stroop DM, Aronson Friedman L, Martin LJ. Genetic architecture of lipid traits changes over time and differs by race: Princeton Lipid Follow-up Study. J Lipid Res. 2014;55:1515-24.

6. Harshfield EL, Koulman A, Ziemek D, Marney L, Fauman EB, Paul DS, Stacey D, Rasheed A, Lee JJ, Shah N, et al. An Unbiased Lipid Phenotyping Approach To Study the Genetic Determinants of Lipids and Their Association with Coronary Heart Disease Risk Factors. J Proteome Res. 2019; 18:2397-410.

7. Mahley RW, Rall SC Jr. Apolipoprotein E: far more than a lipid transport protein. Annu Rev Genomics Hum Genet. 2000;1:507-37.

8. Chen Y, Strickland MR, Soranno A, Holtzman DM. Apolipoprotein E: Structural Insights and Links to Alzheimer Disease Pathogenesis. Neuron. 2021;109:205-21.

9. Radwan ZH, Wang X, Waqar F, Pirim D, Niemsiri V, Hokanson JE, Hamman RF, Bunker CH, Barmada MM, Demirci FY, Kamboh MI. Comprehensive evaluation of the association of APOE genetic variation with plasma lipoprotein traits in U.S. whites and African blacks. PLoS One. 2014;9: e114618.

10. Bennet AM, Di Angelantonio E, Ye Z, Wensley F, Dahlin A, Ahlbom A, Keavney B, Collins R, Wiman B, de Faire U, Danesh J. Association of apolipoprotein E genotypes with lipid levels and coronary risk. Jama. 2007; 298:1300-11.

11. Han S, Xu Y, Gao M, Wang Y, Wang J, Liu Y, Wang M, Zhang X. Serum apolipoprotein $E$ concentration and polymorphism influence serum lipid levels in Chinese Shandong Han population. Med (Baltim). 2016;95:e5639. 
12. Wang X, Magkos F, Mittendorfer B. Sex differences in lipid and lipoprotein metabolism: it's not just about sex hormones. J Clin Endocrinol Metab. 2011;96:885-93.

13. Link JC, Reue K. Genetic Basis for Sex Differences in Obesity and Lipid Metabolism. Annu Rev Nutr. 2017;37:225-45.

14. Liu HH, Li JJ. Aging and dyslipidemia: a review of potential mechanisms. Ageing Res Rev. 2015;19:43-52.

15. Taylor KC, Carty CL, Dumitrescu L, Buzkova P, Cole SA, Hindorff L, Schumacher FR, Wilkens LR, Shohet RV, Quibrera PM, et al. Investigation of gene-by-sex interactions for lipid traits in diverse populations from the population architecture using genomics and epidemiology study. BMC Genet. 2013;14:33

16. Weiss LA, Pan L, Abney M, Ober C. The sex-specific genetic architecture of quantitative traits in humans. Nat Genet. 2006;38:218-22.

17. Liu X, Zhan W, Wu Q, Wang F, Yang B, Ou Q. Polymorphism and plasma levels of apolipoprotein $E$ and the risk of aneurysmal subarachnoid hemorrhage in a Chinese population: a case-control study. Lipids Health Dis. 2018;17:115

18. Torres-Valadez R, Ramos-Lopez O, Frías Delgadillo KJ, Flores-García A, Rojas Carrillo E, Aguiar-García P, Bernal Pérez JA, Martinez-Lopez E, Martínez JA, Zepeda-Carrillo EA. Impact of APOE Alleles-by-Diet Interactions on Glycemic and Lipid Features- A Cross-Sectional Study of a Cohort of Type 2 Diabetes Patients from Western Mexico: Implications for Personalized Medicine. Pharmgenomics Pers Med. 2020;13:655-63.

19. Qin Y, Jing C, Lu L, Hu B, Du P. Does the geographical gradient of ApoE4 allele exist in China? A systemic comparison among multiple Chinese populations. MOL BIOL REP. 2011;38:489-94.

20. Schiele F, De Bacquer D, Vincent-Viry M, Beisiegel U, Ehnholm C, Evans A, Kafatos A, Martins MC, Sans S, Sass C, et al. Apolipoprotein E serum concentration and polymorphism in six European countries: the ApoEurope Project. Atherosclerosis. 2000;152:475-88.

21. Hu D. Dyslipidemia and Management of Atherosclerotic Cardiovascular Diseases in China: New Evidence and New Guidelines. Cardiovascular Innovations Applications. 2017;2:143-5.

22. Guan S, Yang J, Tang Z, Fang X, Wu X, Sun F, Liu H, Chan P. The relationship between apolipoprotein (apo) E polymorphism and lipid changes: An 8-year cohort study in Beijing elderly persons. Arch Gerontol Geriatr. 2012;55:713-7.

23. Willer CJ, Schmidt EM, Sengupta S, Peloso GM, Gustafsson S, Kanoni S, Ganna A, Chen J, Buchkovich ML, Mora S, et al. Discovery and refinement of loci associated with lipid levels. Nat Genet. 2013;45:1274-83.

24. Teslovich TM, Musunuru K, Smith AV, Edmondson AC, Stylianou IM, Koseki M, Pirruccello JP, Ripatti S, Chasman DI, Willer CJ, et al. Biological, clinical and population relevance of 95 loci for blood lipids. Nature. 2010;466:707-13.

25. Marais AD. Apolipoprotein E in lipoprotein metabolism, health and cardiovascular disease. Pathology. 2019;51:165-76.

26. Zhen J, Huang X, Van Halm-Lutterodt N, Dong S, Ma W, Xiao R, Yuan L. ApoE rs429358 and rs7412 Polymorphism and Gender Differences of Serum Lipid Profile and Cognition in Aging Chinese Population. Front Aging Neurosci. 2017:9:248.

27. Freitas RG, Campana EM, Pozzan R, Brandão AA, Brandão AP, Magalhães ME, Silva DA. APOE and LDLR Gene Polymorphisms and Dyslipidemia Tracking. Rio de Janeiro Study. Arq Bras Cardiol. 2015;104:468-74.

28. Carvalho-Wells AL, Jackson KG, Gill R, Olano-Martin E, Lovegrove JA, Williams CM, Minihane AM. Interactions between age and apoE genotype on fasting and postprandial triglycerides levels. Atherosclerosis. 2010;212:481-7.

29. Lampropoulou M, Chaini M, Rigopoulos N, Evangeliou A, PapadopoulouLegbelou K, Koutelidakis AE. Association Between Serum Lipid Levels in Greek Children with Dyslipidemia and Mediterranean Diet Adherence, Dietary Habits, Lifestyle and Family Socioeconomic Factors. Nutrients. 2020; 12(6):1600.

30. Weisgraber KH, Innerarity TL, Mahley RW. Abnormal lipoprotein receptorbinding activity of the human $\mathrm{E}$ apoprotein due to cysteine-arginine interchange at a single site. J Biol Chem. 1982;257:2518-21.

31. Martínez-Martínez AB, Torres-Perez E, Devanney N, Del Moral R, Johnson LA Arbones-Mainar JM. Beyond the CNS: The many peripheral roles of APOE. Neurobiol Dis. 2020;138:104809.

32. Phillips MC. Apolipoprotein E isoforms and lipoprotein metabolism. IUBMB Life. 2014:66:616-23.
33. Steinmetz A, Jakobs C, Motzny S, Kaffarnik H. Differential distribution of apolipoprotein $\mathrm{E}$ isoforms in human plasma lipoproteins. Arteriosclerosis. 1989;9:405-11.

34. Rensen PC, van Berkel TJ. Apolipoprotein E effectively inhibits lipoprotein lipase-mediated lipolysis of chylomicron-like triglyceride-rich lipid emulsions in vitro and in vivo. J Biol Chem. 1996;271:14791-9.

35. Scicchitano P, Cameli M, Maiello M, Modesti PA, Muiesan ML, Novo S. Nutraceuticals and dyslipidaemia: Beyond the common therapeutics. J Funct Foods. 2014:6:11-32

\section{Publisher's Note}

Springer Nature remains neutral with regard to jurisdictional claims in published maps and institutional affiliations.
Ready to submit your research? Choose BMC and benefit from:

- fast, convenient online submission

- thorough peer review by experienced researchers in your field

- rapid publication on acceptance

- support for research data, including large and complex data types

- gold Open Access which fosters wider collaboration and increased citations

- maximum visibility for your research: over $100 \mathrm{M}$ website views per year

At $\mathrm{BMC}$, research is always in progress.

Learn more biomedcentral.com/submissions 